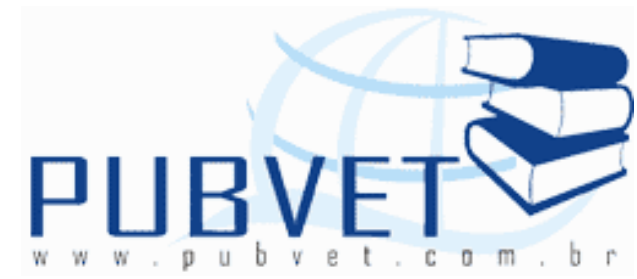

PUBVET, Publicações em Medicina Veterinária e Zootecnia.

\title{
Fatores determinantes do fluxo sanguíneo e nutriente para a glândula mamária bovina
}

\footnotetext{
Alan Soares Machado ${ }^{1}$, Milton Luiz Moreira Lima ${ }^{2}$, Marcelo Marcondes de Godoy ${ }^{3}$, Ivanir Antônio da Silva ${ }^{4}$, Wilian Henrique Diniz Buso ${ }^{1}$, Ernane Peixoto de Araújo $^{5}$
}
${ }^{1}$ Aluno de doutorado da Escola de Veterinária da Universidade Federal de Goiás (EV/UFG)
${ }^{2}$ Professor Dr. da EV/UFG
${ }^{3}$ Professor Dr. do IFGoiano - Campus Ceres
${ }^{4}$ Coordenador do Setor de Produção do IFGoiano Campus-Ceres
${ }^{5}$ Aluno de Mestrado EV/UFG

\section{Resumo}

O fluxo sanguíneo mamário é um dos principais determinantes do substrato fornecido para a síntese de leite, portanto há uma relação estreita entre fluxo sanguíneo mamário e produção de leite. A despeito do papel central que a lactação desempenha, muito ainda tem que ser estudado sobre a glândula mamária, em especial o que a nutrição pode contribuir para modular o aumento do fluxo sanguíneo. Assim o objetivo da elaboração dessa revisão é procurar maior compreensão sobre alguns fatores nutricionais e hormonais, que interferem no fluxo sanguíneo da glândula mamária. 


\title{
Factors determining the blood flow and nutrient for bovine mammary gland
}

\begin{abstract}
The mammary blood flow is a major determinant of the substrate provided for the synthesis of milk, so there is a close relationship between blood flow and breast milk production. Despite the central role that breastfeeding plays, much remains to be studied on the mammary gland, in particular that nutrition can contribute to modulate the increased blood flow. So the goal of this revision is to seek greater understanding of nutritional and hormonal factors that affect blood flow in the mammary gland.
\end{abstract}

\section{INTRODUÇÃO}

Há milhares de anos, bovinos, ovinos, caprinos e bubalinos foram domesticados, e o leite proveniente dessas espécies tornou-se um alimento nutricionalmente importante na dieta humana. Atualmente, é o leite de vaca o mais amplamente utilizado na alimentação humana.

Em razão da importância do leite na alimentação humana, este ganha posição de destaque, tornando-se um importante objeto de pesquisa, tendo em vista que há uma grande preocupação em aumentar a produtividade, qualidade e o lucro na atividade leiteira.

Para desempenhar sua função, a glândula mamária evoluiu tornando altamente ramificada, formando uma estrutura composta e túbero-alveolar, que tem a capacidade de síntese e armazenagem do leite. Para a realização da síntese do leite é altamente necessário que haja um intenso fluxo sanguíneo nas glândulas mamárias, pois a síntese de leite requer grande quantidade de nutrientes, tornando necessário estudo mais aprofundado nessa área (SANTOS \& FONSECA, 2007). 
MACHADO, A.S. et al. Fatores determinantes do fluxo sanguíneo e nutriente para a glândula mamária bovina. PUBVET, Londrina, V. 5, N. 21, Ed. 168, Art. 1131, 2011.

BAUMAN et al. (2006), comentaram que essa área de estudo foi responsável em parte, pelo aumento da produtividade do rebanho nos EUA, nos últimos 25 anos.

Segundo (PROSSER et al., 1996), o fluxo sanguíneo mamário está relacionado com a atividade metabólica da glândula mamária.

O fluxo sanguíneo mamário é um dos principais determinantes da taxa de substrato fornecido para a síntese de leite (DAVIS \& COLLIER, 1985). Há um fluxo maior para o fígado e intestino (LOMAX \& BAIRD, 1983), facilitando a digestão e absorção dos nutrientes, e também para a glândula mamária (DAVIS \& COLLIER, 1985), portanto, favorecendo a utilização preferencial de nutrientes para a síntese de leite. Existe uma relação estreita entre fluxo sanguíneo mamário e produção de leite.

Alguns mecanismos são determinantes no fluxo sanguíneo da glândula mamária entre eles: o efeito galactopoiético do hormônio do crescimento $(\mathrm{GH})$ é bem conhecido e é associada a um aumento no fluxo sanguíneo e de Fator de crescimento insulina I (IGF-I), (MERPHAM et al., 1984; PROSSER et al., 1989; LACASSE et al., 1994), o efeito ambiental, quando os bovinos leiteiros são expostos a temperatura fora de sua zona de termoneutralidade tendem a efetuar ajustes metabólicos e um desses ajustes é a redução do fluxo sanguíneo (COLLIER, et al., 1982) e efeitos nutricionais, a variação na intensidade e na qualidade da alimentação pode alterar a secreção de hormônios e constituintes do leite (MORAES, 2010).

A despeito do papel central que a lactação desempenha, muito ainda tem que ser estudado sobre a glândula mamária, em especial o que a nutrição pode contribuir para modular o aumento do fluxo sanguíneo, assim o objetivo da elaboração dessa revisão é procurar maior compreensão sobre alguns fatores nutricionais e hormonais, que interferem no fluxo sanguíneo da glândula mamária. 
MACHADO, A.S. et al. Fatores determinantes do fluxo sanguíneo e nutriente para a glândula mamária bovina. PUBVET, Londrina, V. 5, N. 21, Ed. 168, Art. 1131, 2011.

\section{REVISÃO DE LITERATURA}

O úbere é uma glândula secretora composta por quatro quartos mamários funcionalmente separados, revestidos pela pele, que oferece pequeno suporte mecânico, mas não suficiente para proteger o úbere. Os quartos mamários anteriores do úbere pesam cerca de $2 / 3$ dos quartos posteriores, o que se traduz em maior produção de leite dos quartos posteriores (MORAES, 2010).

Na vaca adulta o tamanho do úbere não está necessariamente, associado à maior capacidade de produção de leite. Em novilhas, ocorre rápido crescimento durante a primeira prenhez e dessa forma o tamanho do úbere é um indicador limitado da capacidade futura de produção (SANTOS \& FONSECA, 2007).

O sistema de suporte dessa glândula é feito por um conjunto de tecidos que fornecem sustentação à glândula mamária, destacando-se os ligamentos suspensórios mediano e lateral.

A glândula mamária corresponde a uma glândula sudorípara modificada que secreta leite para nutrição da prole, que teve sua origem do espessamento linear bilateral do ectoderma ventrolateral na parede abdominal que formam as "linhas lácteas" ou "cristas mamárias" nas quais se formam os botões mamários que dão origem a porção funcional da glândula mamária (LARSON, 1985).

Essa glândula é composta por um sistema de ductos que conectam nas massas de epitélio secretor chamado de parênquima, que estão envolvidos por tecido conjuntivo ou gorduroso, denominado de estroma. O conjunto encontrase sustentado por uma cápsula fibro-elástica (MORAES, 2010).

A proporção parênquima/estroma é controlada por mecanismo hormonal. Durante a lactação a vaca tem maior quantidade de parênquima que estroma, ocorrendo o inverso no período seco (SANTOS \& FONSECA, 2007). 
MACHADO, A.S. et al. Fatores determinantes do fluxo sanguíneo e nutriente para a glândula mamária bovina. PUBVET, Londrina, V. 5, N. 21, Ed. 168, Art. 1131, 2011.

Embora a glândula mamária seja basicamente semelhante em todos os mamíferos, há amplas variações entre espécies no aspecto da glândula e nas quantidades relativas dos componentes excretados.

De acordo com NORO (2001), os precursores do leite (glicose, ácidos graxos voláteis, gordura corporal, aminoácidos, minerais e vitaminas) são captados pelas células secretoras a partir do sangue através da membrana basal e lateral, e os componentes do leite são secretados via membrana apical. Com a secreção dos componentes lácteos para dentro do lúmen alveolar, ocorre também a migração de água do sangue para o lúmen, de forma a manter a pressão osmótica estável.

A rota do coração para a glândula mamária se dá por meio da aorta caudal, artérias ilíacas comuns direita e esquerda, artérias ilíacas externas e artérias pudentas externas. As artérias mamárias que se originam das artérias pudentas (Figura 3), externas formam ramos craniais e caudais que suprem as porções cranial e dorsal do úbere. Numerosos ramos desses vasos fornecem sangue para todas as partes da glândula mamária. A drenagem sanguínea do úbere da vaca é feita pelas veias pudendas externas, veia abdominal externa, e veia perineal. As duas metades do úbere (direita e esquerda) recebem suprimento sanguíneo das artérias pudendas externas ipsilaterais (MORAES, 2010).

As duas glândulas do mesmo lado da vaca apresentam intercomunicações de vasos sanguíneos e são separadas apenas por um delgado tecido conjuntivo. No entanto, as duas glândulas do lado esquerdo são completamente separadas daquelas do lado direito pelo ligamento suspensório medial, apresentando suprimento sanguíneo, nervoso e ligamentos suspensórios totalmente distintos. Dessa forma, não ocorre mistura de leite ou a transferência de microorganismos de um quarto para outro de forma direta (SANTOS \& FONSECA, 2007).

Após o parto ocorre rapidamente um desvio do fluxo sanguíneo do útero para as glândulas mamárias ocorrendo incremento de duas a seis vezes no 
MACHADO, A.S. et al. Fatores determinantes do fluxo sanguíneo e nutriente para a glândula mamária bovina. PUBVET, Londrina, V. 5, N. 21, Ed. 168, Art. 1131, 2011.

fluxo sanguíneo no período de dois a três dias após o parto (SANTOS \& FONSECA, 2007). O fluxo sanguíneo para o úbere, durante a lactação, é da ordem de $20 \%$ do total bombeado pelo coração (COELHO, 2009).

Um intenso fluxo sanguíneo, no úbere é condição para a alta produção secretória das glândulas mamárias (Tabela 1 ).

TABELA 1- Influência do estado fisiológico da vaca sobre a massa e o fluxo sanguíneo no úbere

\begin{tabular}{llll}
\hline Período & $\begin{array}{l}\text { Massa } \\
(\mathrm{kg})\end{array}$ & do úbere & $\begin{array}{l}\text { Fluxo sanguíneo } \\
\left(\mathrm{L} \mathrm{min}^{-1}\right)\end{array}$ \\
\hline 14 dias antes do parto & 20 & 4,5 \\
Na época do parto & 44 & 21 \\
14 dias após o parto & 33 & 12 \\
\hline
\end{tabular}

Fonte: Adaptado de MORAES (2010)

A síntese de leite requer uma grande quantidade de nutrientes, os quais têm origem na corrente sanguínea, onde estima-se ser necessário o bombeamento de $500 \mathrm{~L}$ de sangue para a glândula mamária para cada litro de leite (SANTOS \& FONSECA, 2007).

O sistema linfático tem a função de remoção da linfa da glândula mamária, a qual se origina da porção sérica do sangue que sai dos capilares, mas não retorna imediatamente e acumula-se nos espaços intersticiais. Os capilares linfáticos drenam a linfa dos tecidos mamários para os linfonodos e destes para vasos linfáticos maiores, os quais se comunicam com o ducto torácico linfático e posteriormente para a veia cava (MORAES, 2010).

\section{EJEÇÃO E DRENAGEM DO LEITE}

A ejeção do leite é um processo ativo de transporte do lume alveolar para a cisterna da glândula, provocada pela contração dos alvéolos em resposta à ligação da ocitocina às células mioepiteliais. A ejeção do leite ocorre 
MACHADO, A.S. et al. Fatores determinantes do fluxo sanguíneo e nutriente para a glândula mamária bovina. PUBVET, Londrina, V. 5, N. 21, Ed. 168, Art. 1131, 2011.

entre 40 segundos e 120 segundos após o estímulo tátil nos tetos, pois quanto mais cheio estiver o úbere, mais rápida será a ejeção do leite (COELHO, 2009).

A liberação da ocitocina (Figura 4) é ocasionada pelos estímulos táteis nos tetos e, em alguns animais, por estímulos auditivos e visuais, como a presença do bezerro. A ocitocina chega às células mioepiteliais 20 a 60 segundos após a estimulação dos tetos (COELHO, 2009).

A liberação de ocitocina da hipófise posterior pode ser inibida em situações de estresse, tais como: ambiente novo para o animal e mudança no sistema de ordenha (manual - mecânica, ou vice - versa). As situações estressantes provocam liberação de adrenalina e noradrenalina, que podem impedir a ocitocina de atingir as células mioepiteliais por vasoconstrição periférica.

Quando ocorre a contração dessas células, sob o estímulo do hormônio ocitocina, o leite contido nos alvéolos é expulso para os ductos maiores e posteriormente para a cisterna da glândula e do teto (COELHO, 2009).

Em cada glândula, o leite é produzido e armazenado em uma cisterna central de aproximadamente, 100 a 400 mL, chamada cisterna da glândula, que é drenado para a cisterna do teto com volume aproximado de 30 a $60 \mathrm{~mL}$, no momento da ordenha. O leite sintetizado continuamente pelas células epiteliais flui para dentro da cisterna da glândula através de aproximadamente 10 a 20 ductos maiores (SANTOS \& FONSECA, 2007).

Cisternas maiores favorecem o armazenamento de leite, influenciando a quantidade de leite produzida na ordenha e permitindo a adoção de intervalos entre ordenhas mais longos (DAVIS et al., 1998; NUDDA et al., 2000). As características morfológicas do úbere podem favorecer o desempenho dos indivíduos ou mesmo das raças (NORMAN \& POWELL, 1988).

Em torno de $80 \%$ do leite sintetizado está armazenado no interior dos alvéolos e nos ductos menores e aproximadamente $20 \%$ está contido na cisterna da glândula e nos ductos maiores (SANTOS \& FONSECA, 2007). 
MACHADO, A.S. et al. Fatores determinantes do fluxo sanguíneo e nutriente para a glândula mamária bovina. PUBVET, Londrina, V. 5, N. 21, Ed. 168, Art. 1131, 2011.

Os ductos da glândula mamária são impermeáveis aos principais constituintes do leite. Não há reabsorção de água nos ductos. Os ductos somente conduzem o leite dos alvéolos para a cisterna da glândula. Por esta razão, a composição iônica do leite é determinada nas células secretoras alveolares e não muda posteriormente (NORO, 2001).

\section{DETERMINANTES DO FLUXO SANGUÍNEO NA GLÂNDULA MAMÁRIA}

Para DAVIS \& COLLIER, (1985), o fluxo sanguíneo (FS) da glândula mamária é um dos principais determinantes da taxa de fornecimento de substrato para a síntese de leite, portanto há uma estreita correlação entre FS na glândula mamária e a produção de leite.

\section{Óxido nítrico}

O óxido nítrico (ON) é uma molécula gasosa simples, altamente lipofílica sintetizado pelas células endoteliais, macrófagos e certo grupo de neurônios do cérebro. Quando diluído, o ON tem uma meia vida de menos de 10 segundos devido à sua rápida oxidação a nitrito e nitrato. O ON liga-se à hemoglobina levando ao término de sua atividade biológica (FLORA FILHO \& ZILBERSTEIN, 2000).

De acordo com LACASSE et al. (1996), o ON é um potente vasorelaxante da vascularização da glândula mamária.

O óxido nítrico é o maior vasodilatador das células endoteliais (WU \& MEININGER, 2000), e desempenha papel importante na regulação do fluxo sanguíneo placentário e, portanto, na transferência de nutrientes e oxigênio da mãe para o feto (BIRD et al., 2003).

O ON é um importante mensageiro intercelular nos mamíferos superiores. O mecanismo de sinalização intercelular é, em geral, realizado através de receptores de membrana celular na célula alvo e habitualmente, são transmembranosos em contato com citoplasma e desencadeando uma 
MACHADO, A.S. et al. Fatores determinantes do fluxo sanguíneo e nutriente para a glândula mamária bovina. PUBVET, Londrina, V. 5, N. 21, Ed. 168, Art. 1131, 2011.

"cascata" de sinais intracelulares que interfere no metabolismo celular. Pelas suas características químicas de alta difusibilidade, a sinalização do ON é exercida diretamente em nível intracelular, sem receptores transmembranosos. Devido à sua penetração intracelular sem intermediários membranosos, o organismo utiliza o ON em funções fisiológicas em que é necessária uma resposta rápida (FLORA FILHO \& ZILBERSTEIN, 2000).

A Arg desempenha múltiplos papéis no metabolismo animal servindo de substrato para a síntese de proteína, como intermediária no ciclo da uréia e como precursora na síntese de vários compostos metabólicos importantes, incluindo o óxido nítrico e poliaminas (WU \& MORRIS, 1998). A arginina é também um potente secretor de hormônios (NEWSHOLME et al., 2005).

A arginina não é somente exigida para a síntese de proteína e detoxificação da amônia, mas também é uma precursora metabólica de muitas moléculas incluindo a prolina, ornitina, poliaminas e ON (WU \& MORRIS, 1998; KIM et al., 2007).

Sabe-se que o ganho de peso da leitegada é correlacionado com a produção de leite ou concentração de nutrientes do leite (KING et al., 1993). O aumento do ganho de peso do leitão ou da leitegada em dietas de porcas suplementadas com arginina (Arg) pode ser um indicativo de aumento da produção de leite ou aumento da concentração de nutrientes no leite. Resultados do estudo de MATEO et al. (2008) indicam que o consumo voluntário e mudanças no peso vivo das porcas não foram afetados pela dieta suplementada com Arg, sugerindo que aumentos na concentração total de aminoácidos (AA) no leite não foram devidos a alterações no consumo alimentar protéico ou mobilização de proteínas corporal.

Baseado na redução dos níveis de uréia no plasma, a suplementação com Arg parece aumentar a eficiência de utilização protéica para a síntese de proteínas do leite. Pelo aumento da síntese de ON (o maior vasodilatador) das células endoteliais dos vasos sanguíneos (WU \& MEININGER, 2000), a suplementação dietética de Arg pode aumentar o fluxo sanguíneo, o 
MACHADO, A.S. et al. Fatores determinantes do fluxo sanguíneo e nutriente para a glândula mamária bovina. PUBVET, Londrina, V. 5, N. 21, Ed. 168, Art. 1131, 2011.

fornecimento de nutrientes para as glândulas mamárias e, a produção de proteínas do leite, e consequentemente aumento do ganho de peso dos leitões lactentes.

MATEO et al. (2008) concluíram que a suplementação dietética de Arg em porcas lactantes aumentou o desempenho dos leitões lactentes. O aumento de ganho de peso da leitegada foi associado com o aumento na concentração total de AA no leite no 70 dia de lactação. Os pesquisadores sugerem que o tratamento com Arg pode aumentar o fluxo sanguíneo mamário e a mobilização de AA durante a lactação.

A (Figura 5) indica a reação química de formação do ON a partir da Larginina.

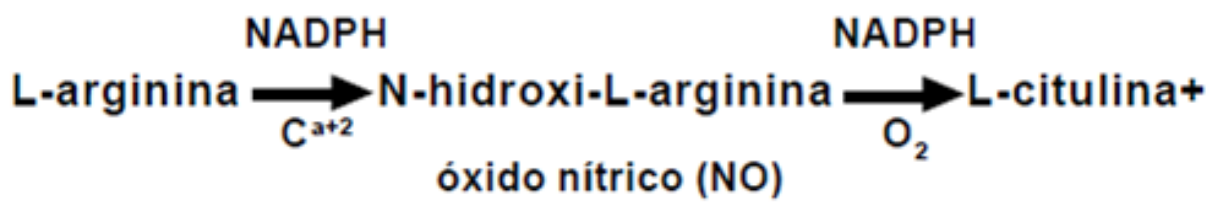

FIGURA 5 - Reação química de formação do ON

Fonte: FLORA FILHO \& ZILBERSTEIN (2000)

A L-arginina é um aminoácido semi-essencial produzido no organismo, porém em quantidade insuficiente para todas as necessidades. Proteínas ingeridas são degradadas até arginina, que podem ser diretamente absorvidas e utilizadas no ciclo da uréia no tecido hepático, ou transformadas no epitélio intestinal em ornitina que, juntamente com a glutamina secretada como glutamato, são convertidas em citrulina. A citrulina absorvida se transforma em arginina no ciclo renal. A citrulina também pode ser convertida diretamente em L-arginina no citoplasma das células endoteliais e dos macrófagos (FLORA FILHO \& ZILBERSTEIN, 2000).

Para FLORA FILHO \& ZILBERSTEIN (2000), muitas células são capazes de sintetizar o ON através de hemeproteínas chamadas de ON síntetases (NOS). 
MACHADO, A.S. et al. Fatores determinantes do fluxo sanguíneo e nutriente para a glândula mamária bovina. PUBVET, Londrina, V. 5, N. 21, Ed. 168, Art. 1131, 2011.

As NOS são dependentes de $\mathrm{O}_{2}, \mathrm{NADPH}$, flavinas e biopterinas para exercer sua atividade. Até o momento, foram isoladas e clonadas três isoenzimas (eNOS, cNOS, iNOS). Esses mesmos autores citam ainda que, a ativação das NOS é determinada pelo cálcio.

O $\mathrm{Ca}^{2+}$ é um importante sinalizador citoplasmático, atuando a partir de ligações com proteínas intracelulares receptoras específicas. Uma destas proteínas citoplasmáticas é a calmodulina, encontrada em praticamente todas as células. Quando $\circ \mathrm{Ca}^{2+}$ se liga à calmodulina forma-se o complexo $\mathrm{Ca}^{2+} /$ calmodulina, este, um elemento regulatório de algumas atividades enzimáticas intracelulares. Quando a concentração intracelular de $\mathrm{Ca}^{2+} \mathrm{cai}_{\text {, }}$ desfaz-se o complexo $\mathrm{Ca}^{2+} /$ calmodulina e a atividade enzimática é desativada. Este mecanismo $\mathrm{Ca}^{2+} /$ calmodulina é responsável pela ativação da NOS (FLORA FILHO \& ZILBERSTEIN, 2000).

LACASSE et al. (1996),em trabalho para a determinação do local de ação do ON e sua ligação com o fluxo sanguíneo na glândula mamária, encontrou a existência da enzima óxido nítrico sintetase (NOS) no epitélio celular da glândula mamária, através da imunorreatividade de estruturas da NADPHdiaforase, abrindo a possibilidade de células produtoras de leite controlar sua própria fonte de sangue e nutrientes através da liberação de ON.

\section{Efeito ambiental}

Pouco é conhecido sobre os efeitos do ambiente sobre o fluxo sanguíneo na glândula mamária, no entanto, o ambiente desempenha um papel importante no metabolismo e tem efeitos sobre o sistema cardiovascular (McGUIRE et al., 1989). A glândula mamária, como glândula de pele, pode estar envolvida na dissipação do calor corporal quando as vacas estiverem em estresse térmico.

Bovinos em lactação, com estresse térmico reduz o consumo de MS (matéria seca), dependendo da severidade do estresse térmico e do tipo de dieta. No estudo de McGUIRE et al. (1989) foi observado que o fluxo de 
MACHADO, A.S. et al. Fatores determinantes do fluxo sanguíneo e nutriente para a glândula mamária bovina. PUBVET, Londrina, V. 5, N. 21, Ed. 168, Art. 1131, 2011.

sangue foi reduzido em $14 \%$ quando os animais tinham estresse térmico em comparação aos animais que tinham conforto térmico. Quando ocorre excitação do animal, a adrenalina diminui o fluxo de sangue para a glândula mamária e reduz a saída de leite (GAONA, 2001). .

A produção de leite é afetada negativamente porque o bovino diminui a ingestão de alimento e o tempo de ruminação. Também, a circulação sangüínea periférica aumenta provocando uma diminuição do fluxo de sangue nos órgãos internos, diminuindo a quantidade de nutrientes para a produção de leite (HAFEZ, 1995).

\section{Efeito hormonal}

Para GAONA (2001), os hormônios envolvidos no crescimento e diferenciação do sistema da glândula mamária estimulam a síntese de DNA (estrógenos), ou a síntese de RNA e proteínas, como a caseína, ação em que a prolactina ( $P R L)$ participa ativamente. Os hormônios em maior grau envolvidos com o processo de crescimento são a PRL e o $\mathrm{GH}$, atualmente classificados na família das somatotropina e, aparentemente, com efeito aditivo.

A PRL está envolvida na iniciação e manutenção da lactação. Tendo as concentrações séricas de PRL correlação positiva, mas de baixo nível com a secreção de leite em bovinos, não sendo possível aumentar a produção de leite mediante administração exógena de PRL (GAONA, 2001).

A ocitocina é sintetiza no hipotálamo e armazenada na hipófise posterior, sendo conhecida como hormônio galactopoiético, responsável pela ejeção do leite, sendo sua secreção inibida pela adrenalina (COELHO, 2009).

A insulina tem como função induzir a utilização de glicose pelas células, além de estimular a síntese de proteínas e lipídios e aumento do acetato no tecido adiposo (GAONA, 2001).

Há ainda, a produção através das células secretoras presentes nos alvéolos de uma proteína de baixo peso molecular, que, de forma autócrina, regula a secreção do leite, chamada de FIL (feedback inhibitor of lactation). 0 
MACHADO, A.S. et al. Fatores determinantes do fluxo sanguíneo e nutriente para a glândula mamária bovina. PUBVET, Londrina, V. 5, N. 21, Ed. 168, Art. 1131, 2011.

efeito da frequência de ordenhas sobre a produção de leite é promovido pela quantidade dessa proteína inibidora no interior do alvéolo. Assim, quando se aumenta o número de ordenhas, passando de uma para duas ou de duas para três ordenhas, ocorre maior esgotamento da glândula mamária, acompanhado de menor concentração da proteína inibidora no interior dos alvéolos, permitindo maior produção de leite. Ao reduzir o número de ordenhas diárias, observa-se maior quantidade desta proteína, que irá determinar uma inibição da secreção do leite (KNIGHT \& DEWHURST, 1994; BAR-PELED et al., 1995).

Essa proteína inibidora é ativa no leite estocado no tecido secretor, mas não no leite presente na cisterna. Consequentemente, vacas que apresentam cisternas com maior capacidade são mais tolerantes ao manejo de uma ordenha que aquelas com cisternas menores (KNIGHT \& DEWHURST, 1994).

Acredita-se também que 0 aumento da pressão intra-alveolar, decorrente da produção de leite e do não-esgotamento adequado da glândula mamária, pode contribuir para a redução da produção (KNIGHT et al., 1992).

\section{Somatotropina bovina}

Também conhecida como BST ou hormônio do crescimento, é um produto natural secretado pela adenohipófise, cuja molécula pode conter 191 aminoácidos (LONDOÑO et al., 1997). Segundo RODRIGUES et al. (2008), o BST possui efeito galactopoiético o qual estimula o fluxo sanguíneo na glândula mamária, modificando a partição dos nutrientes, direcionando-a para a produção de leite.

Os mecanismos envolvidos no efeito galactopoiético do $\mathrm{GH}$ podem ser classificados em três tipos: aumento de síntese da glândula mamária (NIELSEN, 1988); utilização de nutrientes e a mobilização de substratos que fornecem nutrientes essenciais para a síntese do leite (SODERHOLM et al., 1988) e aumento no fluxo sangüíneo para a glândula mamária (MEPHAM et al., 1984). 
MACHADO, A.S. et al. Fatores determinantes do fluxo sanguíneo e nutriente para a glândula mamária bovina. PUBVET, Londrina, V. 5, N. 21, Ed. 168, Art. 1131, 2011.

Para PEEL \& BAUMAN (1987) e MCBRIDE et al. (1988), a resposta de autorregulação provocada por aumento da atividade metabólica do tecido mamário, é um mecanismo pouco conhecido, contribui mais para a captação mamária de precursores do leite do que suas concentrações no mesmo que possivelmente, é o principal mecanismo envolvido.

Para BARBOSA \& MACARI (1993), muitas das atividades do BST exigem a produção prévia de somatomedinas, que via de regra é produzida no fígado, após estimulação pelo BST. Esses compostos têm semelhança com a próinsulina, sendo admitida a designação de fatores de crescimento insulínicos (IGF).

A somatotropina liga-se ao fígado estimulando a produção de IGF-1, permitindo que as células produtoras de leite utilizem os nutrientes para produzir leite. Com níveis mais altos de IGF-1 no sangue as células produtoras de leite, utilizam mais nutrientes e há maior produção de leite.

Existem duas teorias quanto ao modo de ação do IGF-I: a primeira teoria é que o IGF-I aumenta o fluxo sanguíneo mamário diretamente, o que então explica o aumento do metabolismo da glândula mamária. A segunda é que o IGF-I aumenta o metabolismo dentro da glândula mamária, levando a um aumento na síntese dos componentes do leite (PROSSER et al., 1990).

A somatotropina diminui a degradação da proteína muscular e a taxa de glicose absorvida pelas células musculares. Isto permite que o tecido adiposo e a glicose sejam usados para a produção de leite (BAUMAN \& CURRIE, 1980).

O fígado da vaca é um medidor de energia e interpreta quando o consumo de matéria seca não fornece nutrientes suficientes para manter a vaca em BEP (balanço energético positivo). Nessas condições, ele bloqueia muito dos receptores de somatotropina. Logo, o nível de IGF-1 produzido pelo fígado é reduzido devido à redução no número de receptores disponíveis para somatotropina e quando o consumo de matéria seca da vaca é adequado balanço energético positivo há mais receptores disponíveis de somatotropina no fígado (BAUMAN \& McGUIRE, 1994). 
MACHADO, A.S. et al. Fatores determinantes do fluxo sanguíneo e nutriente para a glândula mamária bovina. PUBVET, Londrina, V. 5, N. 21, Ed. 168, Art. 1131, 2011.

O IGF-1 é liberado pelo fígado quando a somatotropina liga-se a receptores especiais no órgão. O IGF-1 liga-se os receptores em células produtoras de leite no úbere permitindo que mais nutrientes da corrente sanguínea entrem na célula. Estes nutrientes adicionais são utilizados para maior produção de leite, aumentando o consumo de ração, pela vaca. Por isso o de matéria seca deve ser maximizado quando se usa a somatotropina bovina recombinante (MARSHMAN \& STREULI, 2002).

No processo de aumento da quantidade secretada de leite, pelo uso do BST, a lactose permanece com a mesma concentração, mas a glândula mamária necessitará de mais glicose para a síntese deste açúcar lácteo, também obtida pela inibição da captação de glicose pelos tecidos periféricos para a formação de gordura corpórea. Por outro lado, o BST provoca aumento da gliconeogênese e, aumento da ingestão voluntária de alimentos, resultando em maior disponibilidade de precursores gliconeogênicos para o organismo (BAUMAN et al.1985; BAUMAN et al.1988; CAMPOS NETO et al.1992).

PEEL \& BAUMAN (1987), relatam que o aumento da produção de leite pelo uso do BST, pode ser devido à melhoria da digestibilidade, alterações na bioenergética de manutenção, síntese do leite e mobilização de nutrientes dos tecidos do corpo para a glândula mamária.

SUÁREZ (1996) avaliou os efeitos da somatotropina bovina sobre a produção de leite e o consumo de matéria seca e constatou aumento de 7,2\% na produção de leite do grupo tratado com $500 \mathrm{mg}$ de BST a cada 14 dias sobre o grupo controle.

A administração de somatotropina promove a utilização imediata das reservas de energia existentes no organismo, como também promove a diminuição na formação de novas reservas adiposas (LUCCI et al., 1998).

CAMPOS NETO et al. (1992) trabalharam com vacas Holandesas recebendo, em um dos tratamentos, $320 \mathrm{mg}$ de BST a cada 14 dias. Mostraram os primeiros autores que a aplicação do produto resultou em 27,1 $\mathrm{kg}$ de leite/dia, aumentando significativamente a produção em $3,3 \mathrm{~kg}$, e os 
MACHADO, A.S. et al. Fatores determinantes do fluxo sanguíneo e nutriente para a glândula mamária bovina. PUBVET, Londrina, V. 5, N. 21, Ed. 168, Art. 1131, 2011.

outros autores obtiveram com o emprego do BST, $24,6 \mathrm{~kg}$ de leite/dia, aumentando a produção em 2,9kg, em relação ao tratamento controle.

Em algumas vacas tratadas com somatotropina, não houveram alterações na porcentagem de gordura, proteína e lactose (BARBANO et al., 1992; BAUMAN, 1992; BAUMAN et al., 1999).

RENNÓ et al. (2006) observaram os tratamentos com aplicação de somatotropina aos 60 e 100 dias pós-parto, que resultaram em grandes diferenças na produção de gordura em relação ao tratamento controle.

\section{Efeito nutricional}

Numerosos tecidos estão envolvidos na absorção e mobilização de nutrientes para satisfazer as necessidades metabólicas da lactação. Para BICKERSTAFFE (1993), esse aporte, se dá a partir do aumento da ingestão da matéria seca (MS) e está normalmente associado com a hipertrofia do fígado, do epitélio intestinal e ruminal.

REYNOLDS et al. (2003), relataram que tais alterações são iniciadas no período que antecedente ao parto e culmina com uma acentuada elevação do aporte de nutrientes no período da lactação em que os requerimentos de nutrientes da glândula mamária excedem ao dos demais tecidos do organismo, pois há aumento da ingestão de alimentos e adaptações orgânicas a fim de assegurar o uso dos nutrientes pela glândula mamária.

Para que os requerimentos glicêmicos sejam supridos, o fígado de vacas em lactação tende a sofrer aumento de $40 \%$, devido especialmente ao incremento dos complexos enzimáticos envolvidos na glicogênese (KELLY et al., 1991). Isso explica parte da elevação dos requerimentos energéticos para mantença dos animais nessa fase, podendo chegar a um incremento de $20 \%$, em relação ao animal não lactante (MOE, 1981). Segundo MAGGIONI et al. (2008), o maior consumo energético aumenta o fluxo sanguíneo hepático.

Segundo ALVES FILHO (2005), a produção de leite em quantidade e qualidade depende principalmente do aporte adequado de proteína e energia 
MACHADO, A.S. et al. Fatores determinantes do fluxo sanguíneo e nutriente para a glândula mamária bovina. PUBVET, Londrina, V. 5, N. 21, Ed. 168, Art. 1131, 2011.

na dieta da vaca em lactação, que diretamente depende do fluxo sanguíneo na glândula mamária, que de acordo com DAVIS \& COLLIER (1985), há diminuição do fluxo sanguíneo em vacas e cabras com jejum de 24 e 48 h.

Quanto mais ácido propiônico é absorvido do rúmen, maior é a produção de leite, pois o mesmo é utilizado pelo organismo da vaca para produção de lactose. Na prática observa-se que, o aumento de concentrado, na dieta eleva a produção de leite e diminuir o teor de gordura no leite (ALVES FILHO, 2005).

Um breve jejum tem pouco efeito sobre as concentrações da maioria dos substratos para síntese do leite, presentes no sangue. No entanto, o fornecimento de substratos para o úbere é reduzido em mais da metade pela redução da fluxo de sangue após jejum de $24 \mathrm{~h}$ (Tabela 2 ). Isto pode ser devido a glândula mamária mediar a produção de um agente vasoativo, que estaria ligado à taxa de síntese do leite (CHAIYABUTR et al., 1980).

TABELA 2 - Efeitos do jejum de $24 \mathrm{~h}$ sobre o fluxo sanguíneo mamário e do débito cardíaco em cabras e vacas em lactação

\begin{tabular}{lllll}
\hline Parâmetros & \multicolumn{2}{c}{ Vaca } & \multicolumn{2}{c}{ Cabra } \\
\cline { 2 - 5 } & Alimentada & Jejum & Alimentada & Jejum \\
\hline $\begin{array}{l}\text { Débito cardíaco, L/min } \\
\text { Fluxo sanguíneo na glândula mamária }\end{array}$ & 45,7 & 35,4 & 5,9 & 3,8 \\
$\begin{array}{l}\text { L/min } \\
\% \text { do fluxo sanguíneo (glândula }\end{array}$ & 7,2 & 3,4 & 0.94 & 0.30 \\
mamária/saída do coração) & 15,8 & 9,6 & 15,9 & 7,9
\end{tabular}

Fonte: Adaptado de CHAIYABUTR et al., (1980)

A inibição da síntese do leite em baixas concentrações de substrato no sangue resultante de jejum pode provocar um aumento da produção de um vasoconstritor local ou uma diminuição da produção de um vasodilatador (DAVIS \& COLLIER, 1985).

O aumento de hormônio GH no plasma de cabras em lactação em jejum, indica um efeito galactopoiético desse hormônio em animais 
MACHADO, A.S. et al. Fatores determinantes do fluxo sanguíneo e nutriente para a glândula mamária bovina. PUBVET, Londrina, V. 5, N. 21, Ed. 168, Art. 1131, 2011.

alimentados, o que pode envolver um mediador secundário (HART et al., 1983).

De acordo com DAVIS \& COLLIER (1985), o aumento do fluxo sanguíneo pela glândula mamária de vacas, em resposta à realimentação fornece um excelente modelo para analisar o controle endócrino do metabolismo mamário e controle local do fluxo sanguíneo mamário (Figura 6).

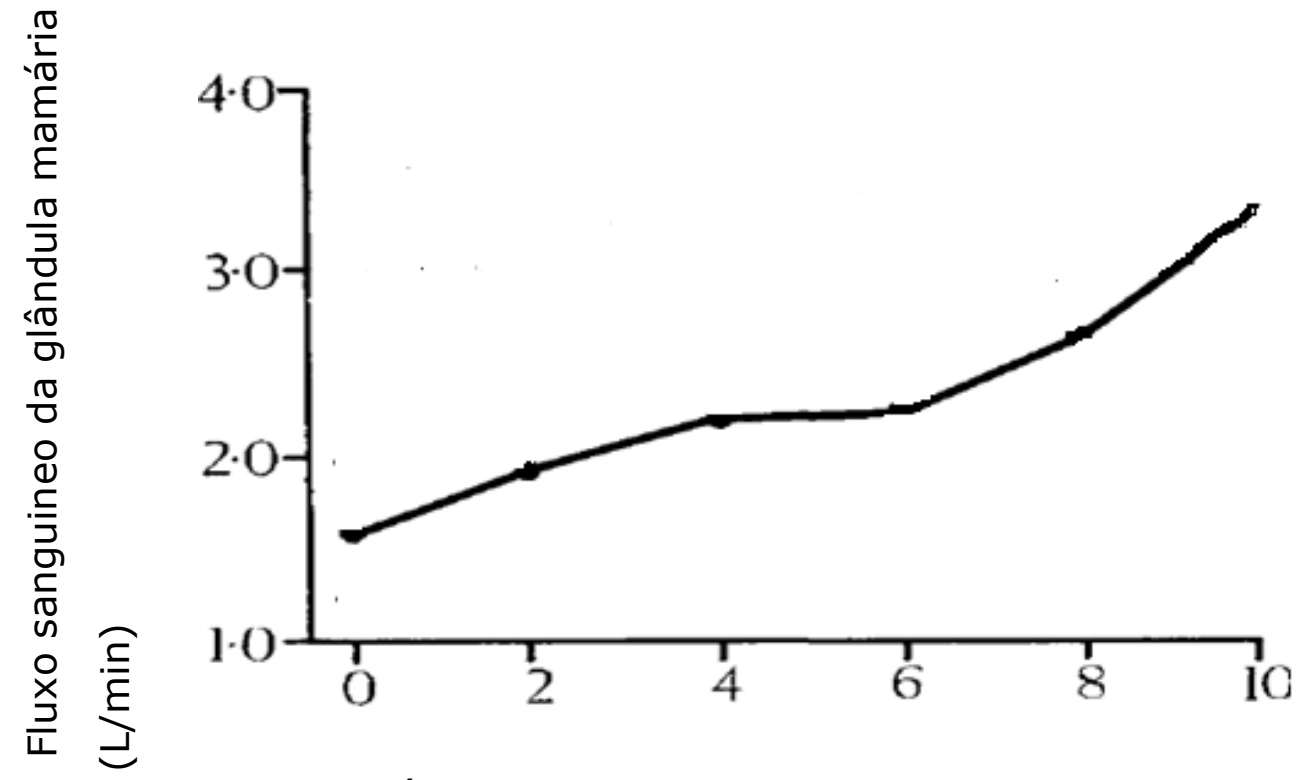

Tempo após a alimentação (h)

FIGURA 6 - Aumentos de fluxo sanguíneo durante a realimentação de quatro vacas da raça Jersey.

Fonte: Adaptado de (DAVIS \& COLLIER, 1985)

\section{CONSIDERAÇÕES FINAIS}

Para os nutricionistas é importante o conhecimento da fisiologia da glândula mamária, em especial sobre o fluxo sanguíneo, para estabelecer ao animal condições ambientais, hormonais e principalmente nutricionais que modulem de forma eficiente a síntese do leite. Através do fluxo sanguíneo é 
MACHADO, A.S. et al. Fatores determinantes do fluxo sanguíneo e nutriente para a glândula mamária bovina. PUBVET, Londrina, V. 5, N. 21, Ed. 168, Art. 1131, 2011.

possível monitorar a composição do leite, importante na prevenção e diagnóstico de alterações que influencie a produção e qualidade do leite.

Logo, a manipulação nutricional e o conhecimento do metabolismo da glândula mamária podem subsidiar estratégias para maximizar a eficiência produtiva dos animais e alterações que visem atender às crescentes exigências mercadológicas que irão possibilitar agregar valor ao produto.

Deve-se, priorizar o conhecimento e o controle dos fatores metabóliconutricional sobre o fluxo sanguíneo na glândula mamária, para melhor compreensão da fisiologia produtiva e composição do leite.

\section{REFERÊNCIAS}

1 ALVES FILHO, D. C. Manipulação da composição da gordura no leite. UFRGS. Porto Alegre-RS. 16p. 2005.

2 BARBOSA, R. T.; MACARI, M. Somatotropina e galactopoiese em vacas leiteiras. Centro de pesquisa de pecuária sudeste, São Carlos - SP. Comunicado técnico no 11, set. p. 1-15. 1993.

3 BAR-PELED, U.; MALTZ, E.; BRUCKENTAL, FOLMAN, Y.; KALI, Y.; GACITUA, H.;LEHRER, A. R.; KNIGTH, C. H.; ROBINSON, B.; VOET, H.; TAGARI, H. Relationship between frequent milking or suckling in early lactation and milk production of high producing dairy cows. Journal of Dairy Science, v.78, n.12, p.2726-2736, 1995.

4 BAUMAN, D. E.; LOCK, A. L. Concepts in lipid digestion and metabolism in dairy cows. In: TRI-STATE DAIRY NUTRITION CONFERENCE, 15. 2006. West Lafayette, Cornell University, Proceedings...2006.14p.

5 BAUMAN, D. E.; EVERETT, R. W.; WEILAND , W. H.; COLLIER, R. J. Production Response to bovine somatotropin in dairy heards in the northeast U.S.A. Department of Animal Science, n. 201, p. 39-48, 1999. 1 CD.

6 BAUMAN, D. E.; McGUIRE, M. A. Paradox of BST: Why Cows Don 't Burn Out. Department of Animal Science, p. 31-39, 1994. 1 CD.

7 BAUMAN, D. E.; PEEL, C. J.; STEINHOUR, W. D.; REYNOLDS, P. J.; TYRREL, H. F.; BROWN, A. C. G.; HAALAND, G. L. Effect of bovine somatotropin on metabolism of lactating dairy cows; influence on rates of irreversible loss and oxidation of glucose and non sterified fatty acids. Journal of Nutrition, v.118, n.8, p.1031, 1988.

8 BAUMAN, D. E.; EPPARD, P. J.; DEGEETER, M. J.; LANZA, G. M. Responses of high producing dairy cows to long term treatment with pituitary somatotropin and recombinant somatotropin. Journal of Dairy Science, v.68, n.6, p.1352, 1985. 
9 BAUMAN, D. E.; CURRIE, W. B. Partitioning of nutrients during pregnancy and lactation: a review of mechanisms involving homeostasis and homeorhesis. Journal of Dairy Science, $v$. 63, p. 1514-1529, 1980.

10 BICKERSTAFFE, R. Regulation of nutrient partitioning in growth and lactation. Australian. Journal of Agricultural Research. Collngwood. v.44, n.2, p.523-539, 1993.

11 BIRD, I.M.; ZHANG, L.B.; MAGNESS, R.R. Possible mechanisms underlying pregnancyinduced changes in uterine artery endothelial function, American Journal of Physiology. $v$. 284, pp. R245-R258, 2003.

12 CAMPOS NETO, O.; RAMOS, A. A.; ESCOBAR, M. J. Avaliação da somatotropina (BST) em vacas leiteiras. Arquivo Brasileiro de Medicina Veterinária e Zootecnia, v.44, n.5, p.41930, 1992.

13 CHAIYABUTR, N.; FAULKNER, A; PEAKER. M. Effect of starvation on the cardiovascular system, water balance and milk secretion in lactating goats. Research in Veterinary Science. 28:291. 1980

14 COELHO, S. G. Glândula mamária e lactação. In: SILVA, J. C. P. M.; OLIVEIRA, A. S. VELOSO, C. M. Manejo e administração na bovinocultura leiteira. Viçosa-MG, 482p. 2009.

15 COLLER, R. J.; BEEDE, D. K.; THATCHER, W. W.; ISRAEL, L. A.; WILCOX, C. J. Influences of environment and its modification on dairy animal health and production. Journal of Dairy Science., 65: 2213-2227. 1982.

16 DAVIS, S. R.; FARR, V.; COPEMAN, P. J. A.; KNIGHT, C. H. STELWAGEN, K. Partitioning of milk accumulation between cisternal and alveolar compartments of the bovine udder: relationship to production loss during once daily milking. Journal of Dairy Research, v.65, p.1-8, 1998.

17 DAVIS, S. R.; COLLIER, R. J. Mammary blood flow and regulation of substrate supply for milk synthesis. Journal of Dairy Science. Savoy, v. 68, n.4, p.1041-1058, 1985.

18 FLORA FILHO, R.; ZILBERSTEIN, B. Artigo de Revisão. Óxido nítrico: o simples mensageiro percorrendo a complexidade. Metabolismo, síntese e funções. Departamento de Gastroenterologia da Faculdade de Medicina da Universidade de São Paulo, São Paulo, SP. Revista da Associação Medica Brasileira. 46(3). p.265-71. 2000.

19 GAONA, R. C. Papéis dos hormônios na lactação. Seminário apresentado a disciplina Bioquímica do Tecido Animal. UFRGS. Porto Alegre - RS. 21p. 2001.

20 HAFEZ, E. S. E. Reprodução Animal. São Paulo: Manole. 1. ed. 1995. 513p.

21 HART, I. C.; MEPHAM, T. B.; MORGAN, J. R. Changes in mammary function and blood hormone concentrations in 24-hour fasted lactating goats. Journal of Physiology. 337:61p. 1983.

22 KELLY, J. M.; SUMMERS, M.; PARK, H. S.; MICLIGAN, L. P.; McBRIDE, B. W. Cellular energy metabolism and regulation. In: Symposium: Nonnmary metabolism in support of lactation and growth. Journal of Dairy Science. Savoy, v.74, n.2, p.678-694, 1991.

23 KIM, S. W.; MATEO, R. D.; YIN, Y. L.; WU, G. Functional amino acids and fatty acids for enhancing production performance of sows and piglets, Asian-Aust. Journal Animal Science, v. 20, pp. 295-306, 2007. 
24 KING, R. H.; TONER, M. S.; DOVE, H.; ATWOOD, C. S.; BROWN. W. G. The response of first-litter sows to dietary protein level during lactation. Journal Animal Science, v. 71, p. 2457-2463, 1993.

25 KNIGHT, C. H.; DEWHURST, R. J. Once daily milking of dairy cows: lationship between yield loss and cisternal milk storage. Journal of Dairy Research, v.61, n.4, p.441-449, 1994.

26 KNIGHT, C. H.; HILLERTON, J. E.; KERR, M. A. Separate and additive stimulation of bovine milk yield by the local and systemic galactopoietic stimuli of frequent milking and growth hormone. Journal of Dairy Research, v.59, n.3, p.243-252, 1992.

27 LACASSE, P.; FARR, V. C.; DAVIS, S. R.; PROSSER, C. G. Local secretion of nitric oxide and the controlo f mammary blood flow. Journal of Dairy Science, v. 79. p. $1369-1374,1996$.

28 LACASSE, P., E. BLOCK, Y. COUTURE, D. PETITCLERC. Bovine growth hormone and the local production of prostacyclin on mammary blood flow in dairy cows. Proceeding... NewZealand Society of Animal Production. 54:111-114. 1994.

29 LARSON, L. B. Lactation. Iowa: The Iowa State University Press/AMES. 1985. 275p.

30 LOMAX, M. A.; G. D. BAIRD. Blood flow and nutrient exchange across the liver and gut of the dairy cows. British Journal of Nutrition. v.49, p.481-496, 1983.

31 LONDOÑO, A. A. S.; VALADARES FILHO, S. C.; SILVA, J. F. C.; PEREIRA, J. C.; CECON, P. R.; FONSECA, F. A.; MATOS, F. N. Somatotropina bovina para vacas de leite em lactação. 1. Produção e composição do leite. Revista Brasileira de Zootecnia, v.26, n.6, p.1227-1233, 1997.

32 LUCCI, C. S.; RODRIGUES, P. H. M.; SANTOS, E. J.; CASTRO, A. L. Emprego da somatotropina bovina (BST) em vacas de alta produção. Journal Veterinary Research Animal Science. v. 35, n. 1, p. 46-50, 1998.

33 MAGGIONI, D; ROTTA, P. P; ITO, R. H; MARQUES, J. A; ZAWADZKI, F; PRADO, R. M; PRADO, I. N. Efeito da nutrição sobre a reprodução de ruminantes: uma revisão. PUBVET, v.2, n11, mar, 2008.

34 MARSHMAN, E.; STREULI, C. H. Insulin-like growth factors and insulin-like growth factor binding proteins in mammary gland function. Breast Cancer Research, v.4, n. 6, p. 231-239, 2002.

35 MATEO, R. D.; WU, G.; MOON, H. K.; CARROLL, J. A.; KIM, S. W. Effects of dietary arginine supplementation during gestation and lactation on the performance of lactating primiparous sows and nursing piglets. Journal of Animal Science., v. 86, p.827-835, 2008.

36 McBRIDE, B. W.; BERTHIAUME, R.; LAPIERRE, H. Nutrient flow in the lactating cow. Utilisation métabolique des nutrients. Canadian Journal of Animal Science. Ottawa, v. 78, n. 1, p.91-104, 1998.

37 McGUiRE, M. A., D. K. BeEDE, M. A. DELORENZO, C. J. WiLCOX, G. B. HUNTINGTON, C. K. REYNOLDS, R. J. COLLIER. Effects oftbermal stress and level of feed intake on portal plasma flow and net fluxes of metabo-lites in lactating Holstein cows. Animal Science. v. 67, p. 1050. 1989 
38 MEPHAM, T. B.; LAWRENCE, S. E.; PETERS, A. R.; HART. I. C. Effects of exogenous growth hormone on mammary function in lactating goats. Hormone and Metabolic Research. v.16, p.248, 1984.

39 MOE, P. W. Energy metabolismo of dairy cattle. Journal of Dairy Science, Savoy, v.64, n. 6, p. 1120-1139, 1981.

40 MORAES, I. A. Glândulas mamárias. Disponível em: http://www.uff.br/fisiovet/Conteudos/glandula_mamaria.htm Acesso: 10 ago.2010.

41 NEWSHOLME, P.; BRENNNAN, L.; RUBI, B.; MAECHLER, P. New insights into amino acid metabolism, beta-cell function and diabetes, Clinical Science., v. 108, p. 185-194, 2005.

42 NIELSEN, M. O. Effect of recombinantly derived bovine somatotropin on mammary gland synthetic capacity in lactating goats. Journal of Animal Physiology and Animal Nutrition, v.59, p.263-272, 1988.

43 NORMAN, H. D.; POWELL, R. L. Phenotypic and genetic relationship between linear functional type traits and milk yield for five breeds. Journal of Dairy Science., v.71, p.1880$1888,1988$.

44 NORO, G. Síntese e secreção do leite. Seminário apresentado a disciplina Bioquímica do Tecido Animal. UFRGS. Porto Alegre - RS. 21p. 2001.

45 NUDDA, A.; PULINA, G.; VALLEBELLA, R. BENCINI, R.; ENNE, G. Ultrasound technique for measuring mammary cistern size of dairy ewes. Journal of Dairy Research, v.67, p.101$106,2000$.

46 PEEL, C. J.; BAUMAN, D. E. Somatotropin and lactation. Journal of Dairy Science., v.70, p. 474-486, 1987.

47 PROSSER, C. G., S. R. DAVIS, V. C. FARR, P. LACASSE. Regulation of blood flow in the mammary microvasculature. Journal of Dairy Science. 79:1184-1197. 1996.

48 PROSSER, C. G., I. R. FLEET, A. N. CORPS, E. R. FROESCH.; R. B. HEAP. Increase in milk secretion and mammary blood flow by intra-arterial infusion of insulin-like growth factor-I into the mammary gland of the goat. Journal of Endocrinology. 126:437-443. 1990.

49 PROSSER, C. G.; I. R. FLEET.; A. N. CORPS. Increased secretion of insulinllike growth factor-I into milk of cows treated with recombinantly-derived bovin growth hormone. Journal of Dairy Research 56:17-26. 1989.

50 RENNÓ, F. P.; LUCCI, C. S.; SILVA, A. G.; RENNÓ, L. N.; RENNÓ, B. P.; CECON, P. R.; BARBOSA, P. F. Efeito da somatotropina bovina recombinante (rBST) sobre o desempenho produtivo e reprodutivo de vacas da raça holandesa. Arquivo Brasileiro de Medicina Veterinária e Zootecnia, v. 58, n. 2, p. 158-166, 2006.

51 REYNOLDS, C. K.; AIKMAN, P. C.; LUPOLI, B.; HUMPHRIES, D. J.; BEEVER, D. E. Splanchnic metabolism of dairy cows during the transition from late gestation through early lactation. Journal of Dairy Science. Savoy, v. 86, n.4, p. 1201-1217, 2003.

52 RODRIGUES, M.; FARO, L. EI.; CARDOSO, V. L.; PAZ, C. C. P. Utilização de somatotropina bovina e seu efeito na avaliação genética de animais da raça Holandesa. In: VII Simpósio Brasileiro de Melhoramento Animal, 2008. São Carlos. Anais... São Carlos. SBMA., p. 1- 4. 2008. 
53 SANTOS, M. V.; FONSECA, L. F. L. Estratégias para controle de mastite e melhoria da qualidade do leite. Barueri: Ed. Manole, 2007. 314p.

54 SODERHOLM, C. G.; OTTERBY, D. E.; LINN, J. G. EHLE, F. R.; WHEATON, J. E.; HANSEN, W. P.; AMEXSTAD, R. J. Effects of recombinant bovine somatotropina on milk production, body composition and physiological parameters. Journal of Dairy Science, v.71, p.355-365, 1988.

55 SUÁREZ, A. Efeito da somatotropina bovina recombinante na produção de leite e consumo de matéria seca em vacas leiteiras. In: REUNIÃO ANUAL DA SOCIEDADE BRASILEIRA DE ZOOTECNIA, 1996. Fortaleza. Anais... Fortaleza: SBZ, 1996. v. 1, p. 150-163.

$56 \mathrm{WU}, \mathrm{G} . ;$ MEININGER, C. J. Arginine nutrition and cardiovascular function, Journal of Nutrition. v. 130, p. 2626-2629, 2000.

57 WU, G.; MORRIS JR, S. M. Arginine metabolism: nitric oxide and beyond, Journal Biochemical, v.336, p. 1-17, 1998. 